\title{
Engineering Application Talents Cultivation of Mechanical Design Manufacturing and Automation Based on Engineering Education Accreditation
}

\author{
Zhang Peng; Fang Bin \\ School of Mechanical and Automotive Engineering \\ Qilu University of Technology \\ Jinan, China \\ sqzhangpeng@163.com
}

\author{
Xu Chonghai; Qiu Shubo \\ School of Mechanical and Automotive Engineering \\ Qilu University of Technology \\ Jinan, China
}

\begin{abstract}
The establishment of engineering education accreditation system, is to achieve the comprehensive, coordinated and sustainable development of Chinese engineering education. It has become a broad consensus on the engineering sector and the education sector. The major of mechanical design manufacturing and automation of Qilu University of Technology is as an example. According to the specialty requirements of < National Engineering Education Accreditation Standards (Trial) $>$ and supplementary requirements in mechanical majors, this paper expounds the construction goal, training goal, characteristics, ideas and measures from the application undergraduate major of mechanical design manufacturing and automation, to cultivate the engineering application talents of mechanical design and manufacturing engineering and automation. Hope to have reference to other related majors in colleges and universities.
\end{abstract}

Keywords-engineering education accreditation; mechanical design manufacturing and automation; engineering application

\section{INTRODUCTION}

With the rapid increase of China economic strength and the rapid development of the culture, science and technology, China is gradually becoming the world manufacturing center. Then, a large number of engineering and technical personnel will need. On the one hand, with the rapid development of China's higher engineering education, the higher requirements for engineering education are put forward. On the other hand, due to the development of economic globalization, the trend of internationalization of higher engineering education is becoming more and more obvious. In this process, how to control quality of engineering education in China, has become the focus of attention of educational circles and engineering circles. [1-2] China became a full member of the international undergraduate engineering degree agreement <Washington Agreement> in June 2016. The engineering education accreditation is the education opportunities and challenges of our higher engineering education [3].

The core idea of engineering education accreditation cultivating talent is to output as a guide, which is from "teacher can teach what" into "what students should achieve." In the university, engineering education is for the preparation of future related work. To determine the reasonable training target to meet the needs of society and science development connotation, the graduation requirements of training goals need to clearly support. The implementation of teaching activities is the center designed to output "students", from engineering knowledge into the occupation training required ability. This is an important transformation of the concept of the cultivation of higher engineering education [4-5].

In this paper, the mechanical design manufacturing and automation major of Qilu University as an example, for the engineering education accreditation, with social and business demand for talent as input, with excellent mechanical engineers as output to meet the demand of social and business, it is expounded that the construction goal, training goal, characteristics, ideas and measures from the application undergraduate major of mechanical design manufacturing and automation. Therefore, it can form the training characteristics of application-oriented undergraduate mechanical major.

\section{CONSTRUCTION GOAL OF THE MAJOR}

According to the specialty requirements of $<$ National Engineering Education Accreditation Standards (Trial) $>$ and supplementary requirements in mechanical majors, in order to cultivate the engineering application talents of mechanical design and manufacturing engineering and automation, teaching reforms of theoretical and practice training are actively carried out, based on actual projects as a platform and engineering application ability training as the main line. Advanced engineering talents can be cultivated, which meet the needs of social development, with light industry characteristics, abilities and qualities of coordinated development. The backbone major can be built with demonstration training effect of engineering application talents.

\section{TRAINING GOAL OF THE MAJOR}

The major is to cultivate the advanced engineering application talents for mechanical engineering professional and technical work, which can master the basic knowledge and skills of mechanical design, manufacturing and mechanical engineering automation, with good humanistic quality and innovative consciousness, with a certain engineering 
consciousness, ability of occupation accomplishment and application technology.

\section{MAJOR CHARACTERISTICS}

The major teaching contents of mechanical design manufacturing and automation is mainly the knowledge about industrial design, mechanical equipment and mechanical and electrical products manufacturing, operation control, the production process management, and which has been focused on the light industrial machinery, food and packaging machinery. With modern design, manufacturing technology as the main line, it is to cultivate talents with electric machine comprehensive knowledge, basic mechanical engineer training, and basic capacity of mechanical and electrical product design, manufacturing and production management.

\section{CONSTRUCTION IDEAS AND MEASURES}

\section{A. Optimize Talent Training Program}

The three-in-one quality conception of "theory teaching + practice teaching + quality development" personnel training is set up, taking ability as the core, to meet the professional engineering education accreditation standards and meet the training objectives of industry demand for talent. The teaching content and teaching method exchanges through similar colleges. And the development trend of teaching reform is mastered.

The establishment of the specialized committee is in the cooperation of university and enterprise and the implementation of "Practice is as important as learning ". In the formulation process of talent training plan, it is need to strengthen the equipment manufacturing industry, especially the joint training of light equipment manufacturing industry, to strengthen multi class enterprise practices of the engineering practice, to strengthen the students' cognitive training, curriculum experiment, curriculum design, comprehensive training, production practice, engineering training, and graduation design, to emphasis on the cultivation of professional knowledge and occupation ability, humanistic quality, scientific quality and social responsibility, to strengthen the discipline foundation and professional basis, and to emphasis on the ability cultivation to solve the engineering problem.

\section{B. Reform the Curriculum System}

It is need to follow the concept of "Widen the diameter, thicken the foundation, pay attention to ability" to cultivate application-oriented undergraduate talents, according to the mechanical design manufacturing and automation professional training objectives and requirements. As the main line of the engineering application ability training, the curriculum system is optimized. The optimization principle is to strengthen the foundation, broaden the professional, and reflect the quality, ability, knowledge, and culture, focusing on interdisciplinary of "machine based, mechanical and electrical integration, reflecting the characteristics of light industry". It is necessary to take the initiative to attract employers to participate in the curriculum system, teaching content design, to build the curriculum system, teaching content and practice teaching system to meet the training standards of engineering applied talents.

The teacher responsibility system is adopted in the course teaching. The teacher of main core curriculum has rich teaching experience and strong ability of teaching reform as the curriculum leader, and leads the research team members to meet curriculum standards of engineering applied talents training requirements. At the same time, by the way of cooperation of university and enterprise, textbooks and handouts of professional courses (for example, mechanical manufacturing technology of hydraulic and pneumatic transmission) are researched and developed. More prominent advantages are appeared by setting up the introduction of light industry machinery, light industrial equipment and complete sets of technology, food and packaging machinery and other light industrial machinery courses.

\section{Innovative Teaching Methods}

To deepen the reform of teaching methods and teaching methods, the establishment of the corresponding research projects, and the construction of democracy, active heuristic, inquiry, research teaching atmosphere, are be done. We pay attention to the construction of multimedia teaching resource library and network assisted teaching platform, and actively try to flip the classroom, massive open online courses (MOOCs) and other new teaching methods. To promote the goal oriented, task driven, teaching methods reform of the organic combination of theory and practice.

According to the requirements of engineering applied talents training, students are guided to improve learning methods, in the teaching of introducing a large number of enterprises practical cases, multidimensional driving the students self-learning ability, scientific thinking ability, strict engineering quality, good ability and strong innovation ability. Every year, the excellent engineer class is set up by the best selection of 40 students from the freshmen of mechanical design and manufacture and automation.

A variety of ways are used to attract undergraduates participating in the teachers' scientific research activities. The establishment of college students' innovative research and training (SIRT) project, and the construction of college science and Technology Innovation Studio, improve their research ability. Educational activities of the students as the main body of the independent practice are strengthened, and social practices closer to the engineering design, manufacture, experiment, practice are organized.

\section{Strengthening the Construction of Teaching Staff}

There are supported to do that teacher training of domestic and foreign, teaching ability training, occupation skill training, management of teaching and students training, employment guidance and training, etc. Academic exchanges update the education concept of teachers, and improve the teaching and application of scientific research ability. Establishment of teaching improvement projects is done to improve the level of the young teachers' teaching and research. The teaching level of theory and practice is up for young teachers through various forms. The young teacher tutorial system is set. In this system, old teachers guide young teachers to carry out teaching 
research, scientific research activities and the preparation of professional teaching materials, which can improve the level of young teachers.

It is to do that taking the combination road of the production, learning and research. The outstanding personnel exchange and cooperation system is established in college and enterprises. Teachers are organized to vigorously carry out scientific and technological research focusing on the application and development of scientific technology research. The establishment of "Dr. +" activities promote the teachers to actively participate in the production technology and rich practical experience.

It is done to introduce the application type talents, especially with high mid-level professional and technical positions in the production, increase high-level talents and double type teacher ratio of more than $40 \%$, train excellent professional leaders, and lead major development. Another is to actively recruit well-known professor, tutors of school enterprise cooperation, the part-time graduate instructors, to strengthen academic cooperation.

Through the combination of introduction and training, the teaching staffs gradually is formed that have the reasonable structure, high level of teaching, deep academic attainments, innovative practice, Full-time and part-time teachers.

\section{E. Perfect Experiment Teaching System}

The construction of teaching practice base outside the school need to be strengthened, in order to build training experimental teaching system that is a comprehensive design application organic combination of professional education and entrepreneurship education, with an integration of basic skills, professional skills and technical application, to meet the needs of cultivating students' practical skills and innovative ability.

Through a variety of ways to cooperate with enterprises, the construction of laboratory, practice training base and teaching practice platform is strengthened. One role model of experimental teaching center and one college students' practical education base are built. In student enterprise learning phase, college and enterprise set up a joint coordination group, and select the engineering and technical personnel of rich engineering experience, strong responsibility sense as curriculum teachers and graduate design guidance teachers. Combined with extracurricular science and technology activities, competition, professional skills certification (SolidWorks professional engineer certification, CAD engineer certification, etc.), and a reasonable increase in the proportion of practical teaching, it is sure that the necessary credits and hours of professional practice teaching.

To ensure that the basic requirements of the students' innovation and entrepreneurship education, the establishment of innovation and invention patent applications, methods and skills, knowledge economy and innovation, and entrepreneurship curriculum, promote the integration of professional education and entrepreneurship education, and promote innovation and entrepreneurship education throughout the entire process of personnel training.

The system of practice teaching quality evaluation and management is further improved, to improve the teaching quality of experimental teaching, practice, practice and graduation design or thesis. Part of practice teaching is done through the implementation of double tutors. According to the need, a joint steering group is set up for more targeted guidance.

\section{CONCLUSION}

For the engineering education accreditation, in professional construction, according to college's own conditions and engineering requirements of the ability of students, through the depth of cooperation with local governments and enterprises, it's explored that the road of engineering applied talents training for mechanical design manufacturing and automation major of local college.

\section{REFERENCES}

[1] Yu Fengyun,Liu Yuanlin,Zhang Wensheng,etc, "Thoughts on the Construction of Mechanical Engineering Specialty in Applied Undergraduate,"China Electric Power Education. vol. 2 pp. 73-74, February,2014.

[2] Lin Jian, "Quality Evaluation of "Excellent Engineer Education and Training Program" Based on Engineering Education," Research in Higher Education of Engineering.vol.5 pp.35-45,September,2014.

[3] [EB/OL].http://edu.sina.com.cn/1/2016-06-02/docifxsvenv6358291.html.

[4] Jia Weiping, "The Construction of the Training System of Applied Mechanical Talents' Engineering Ability in the Background of Engineering Education Certification," Experimental Technology and Management.vol.1 pp.38-40,January,2015.

[5] Zhang Xiaohong, Li Jianbin, "Research on the Mode of Cultivating School-Enterprise Cooperation of Mechanical Talents in Local Colleges and Universitie," Theory and Practice of Contemporary Education.vol.7 pp.60-62,June, 2016. 